NBER WORKING PAPER SERIES

\title{
WHEN DO RESEARCH CONSORTIA WORK WELL AND WHY? EVIDENCE FROM JAPANESE PANEL DATA
}

\author{
Lee G. Branstetter \\ Mariko Sakakibara \\ Working Paper 7972 \\ http://www.nber.org/papers/w7972 \\ NATIONAL BUREAU OF ECONOMIC RESEARCH \\ 1050 Massachusetts Avenue \\ Cambridge, MA 02138 \\ October 2000
}

\begin{abstract}
The ordering of authors' names was determined by a coin toss. We thank the late Zvi Griliches, Colin Cameron, Iain Cockburn, Wesley Cohen, Rebecca Henderson, Adam Jaffe, Oscar Jorda, Michael Katz, Samuel Kortum, Joshua Lerner, Kevin McCardle, Peter Reiss, David Weinstein, Ryuhei Wakasugi, an anonymous referee, and participants in the 1999 NBER Summer Institute, the Fifth Annual Berkeley-Stanford Conference in Industrial Organization and the 2000 Annual Meeting of the American Economic Association in Boston for useful comments and suggestions. To protect the confidentiality of our interviewees, we are unable to acknowledge by name the government officials and firm managers we interviewed in Japan to obtain invaluable insights on how MITI research consortia actually operated. We are also grateful to the Japanese Patent Office for helping us create a mapping linking the technological goals of Japanese research consortia with the International Patent Classification system and the Japan Patent Information Organization for providing us with detailed Japanese patent data. We would like to thank Heather Berry, Natasha Hsieh, Jina Kang, Yumiko Kawanishi, Hiau-Looi Kee, Jon Wolf, and, especially, Kaoru Nabeshima for their outstanding research assistance. This project received financial support from the Sloan Foundation, the Center for Global Partnership, the Social Science Research Council, the Center for International Business Education and Research at the UCLA Anderson Graduate School of Management and the Academic Senate of the University of California. Finally, much of the research was first undertaken as part of a research contract performed for the Advanced Technology Program of the Department of Commerce under the administration of the NBER. The views and opinions expressed in this paper, however, are purely those of the authors, not those of any sponsoring organization, the NBER, or the U.S. Advanced Technology Program.
\end{abstract}

(C) 2000 by Lee G. Branstetter and Mariko Sakakibara. All rights reserved. Short sections of text, not to exceed two paragraphs, may be quoted without explicit permission provided that full credit, including (C) notice, is given to the source. 
When Do Research Consortia Work Well and Why? Evidence from Japanese Panel Data

Lee G. Branstetter and Mariko Sakakibara

NBER Working Paper No. 7972

October 2000

JEL No. O32, O31, L52

\begin{abstract}
We examine the impact of a large number of Japanese government-sponsored research consortia on the research productivity of participating firms by measuring their patenting in the targeted technologies before, during, and after participation. Consistent with the theoretical predictions of Katz (1986) and others, we find consortium outcomes are positively associated with the level of potential R\&D spillovers within the consortium and (weakly) negatively associated with the degree of product market competition among consortium members. Furthermore, our evidence suggests that consortia are most effective when they focus on basic research.
\end{abstract}

Lee G. Branstetter

Department of Economics

University of California, Davis

Davis, CA 95616

and NBER

branstet@ucdavis.edu
Mariko Sakakibara

Andersen Graduate School of Management University of California, Los Angeles

Los Angeles, CA 90024

mariko.sakakibara@anderson.ucla.edu 


\section{Introduction}

If technological innovation is the most important force driving economic growth in the long run, then public policies designed to promote and encourage technological innovation take on substantial importance. This paper investigates the impact of Japan's decades-old experiment with one such policy instrument: publicly organized and supported research consortia. There is a long-standing debate concerning the role these consortia have played in Japan's technological development. This debate has implications beyond Japan's borders, because Japanese research consortia have been and continue to be emulated by nations in Europe, North America, and elsewhere in Asia. ${ }^{1}$

Following Spence (1984), a large theoretical literature has developed over the last decade that has analyzed the possible benefits of research consortia as tools by which R\&D externalities could be internalized. Important contributions to the theory of research consortia include Katz (1986), d'Aspremont and Jacquemin (1988), Suzumura (1992), Kamien, Muller, and Zang (1992), Kamien and Zang (2000), Leahy and Neary (1997), and Katsoulacos and Ulph (1998), among others. Much of this theoretical literature has sought to identify the conditions under which consortia are likely to lead to welfare-improving outcomes. Up to this point, however, little has been done to confront the empirical predictions or implications of this literature with data in a systematic way. ${ }^{2}$ In this paper, we seek to address this gap between theory and empirical analysis.

\footnotetext{
${ }^{1}$ For example, in the United States, the passage of the National Cooperative Research and Production Act in 1993 lowered antitrust legal barriers to the formation of research consortia by competing firms, and the Advanced Technology Program of the U.S. Department of Commerce has spent several hundred million dollars over the course of the 1990s promoting precommercial research by private firms, much of it in the context of research consortia. Public support of research consortia also continues in Europe and in Japan itself.

2 Though there has been empirical work on research consortia, it has tended to be qualitative or descriptive rather than econometric (e.g., Callon, 1995; Ham and Mowery, 1995). Much of the past econometric work has focused on
} 
We examine the impact of a large number of Japanese government-sponsored research consortia on the research productivity of participating firms by measuring their patenting in the targeted technologies before, during, and after participation. ${ }^{3}$ Our rich data set enables us to examine this impact at several different levels of aggregation, so that we can address issues of causality, sample selection, and the unmeasured heterogeneity of participating firms. Consistent with the predictions of much of the theoretical literature, we find that consortium outcomes are positively associated with the level of potential $\mathrm{R} \& \mathrm{D}$ spillovers within the consortium and generally negatively associated with the degree of product market competition among consortium members, though this latter relationship is less statistically robust. Furthermore, our evidence suggests that these consortia are most effective when they focus on basic research.

The rest of the paper proceeds as follows. Section 2 summarizes the theoretical predictions of Katz (1986) and presents the empirical propositions derived from it. Section 3 provides some background information on government-sponsored research consortia in Japan, on which our empirical analysis is based. Section 4 describes our data and our empirical framework for estimating the overall impact of research consortia over time. Section 5 describes our approach to estimating the relationship between consortium characteristics and consortium outcomes and presents the results. Finally, Section 6 presents our conclusions.

\section{Theoretical predictions and empirical propositions}

For concreteness, we review the basic features of one early contribution to the theory of research consortia - Katz (1986) — and illustrate its empirical implications. However, these

a single research consortium, such as in Irwin and Klenow (1996). We know of no econometric studies which have attempted to directly assess the empirical implications of Katz's theory.

3 This approach is more direct than that taken in Branstetter and Sakakibara (1998), which was also an econometric study that measured the impact of research consortia on the innovative output of participating firms. 
implications also emerge from the other key papers in this theoretical literature. In Katz's 4stage game, firms in an industry first decide whether or not to participate in R\&D consortia. In the second stage, firms choose the rules for sharing $R \& D$ costs and outputs. Taking the rules as given, each firm then chooses its level of R\&D investment in the third stage. Firms achieve some result from their $\mathrm{R} \& \mathrm{D}$ effort, parameterized as a reduction in the marginal cost of output. Firms then set production levels non-cooperatively in the final stage.

The welfare impact of research consortia depends on the values of two key attributes. The first of these is the level of $R \& D$ spillovers within a consortium. In these models, the "effective" $R \& D$ of a firm is the sum of its own $R \& D$ expenditure and the $R \& D$ spillovers it receives through participation in a research consortium. ${ }^{4}$ Through these R\&D spillovers, firms can realize cost reductions (the "output" of R\&D) above and beyond what they could obtain if they had to rely solely on their own R\&D expenditures. ${ }^{5}$ In general, the greater the potential level of R\&D spillovers within consortia, the greater the equilibrium level of R\&D expenditure by member firms. However, Katz points out that under certain conditions, R\&D consortia can be welfare enhancing - even when they reduce the actual level of R\&D expenditure - because the effective level of R\&D (and therefore, R\&D output) is raised through spillovers. Higher levels of effective $R \& D$ lead directly to higher levels of welfare since, in these models, $\mathrm{R} \& \mathrm{D}$ reduces production costs, increases output, and lowers prices.

The second key attribute is the level of ex-post product market competition among the firms participating in the research consortium. Some - perhaps all — of the private benefits of

\footnotetext{
4 It is useful to emphasize that consortia have effects on both R\&D input (the actual resources expended by the participating firms) and R\&D output (the results of that expenditure).

${ }^{5}$ While Katz only considers the case in which R\&D spillovers are "substitutes" for own firm R\&D, we allow for the possibility of technological complementarity. In such a case, the R\&D activities of other firms could actually raise the productivity of the firm's own R\&D expenditure. The work of Levin and Reiss (1988), Cohen and Levinthal
} 
cooperative $\mathrm{R} \& \mathrm{D}$, in terms of raising firm profits, could be dissipated through product market competition. When the level of product market competition among participating firms is intense, the gain in profits to a single participating firm through reduced production costs is negated by the accompanying fall in the costs of its rivals. In this case, the principal effect of cooperative research is to lower the product price and raise consumer surplus, not profits. Anticipating this outcome, firms will seek to set lower levels of R\&D in the cooperative "consortium" stage than would obtain in an equilibrium without research consortia. Ceteris paribus, a greater level of competition reduces the effective level of $R \& D$ input, and thus reduces $R \& D$ output, leading to a decrease in welfare.

The net impact of R\&D consortia will depend, in a critical way, on the values of these two key attributes. The key innovation of our paper is that we provide quantitative measures of these attributes for individual research consortia. Thus, we can empirically estimate the impact of these attributes on the $R \& D$ output of the participating firms in linear and nonlinear regression models, controlling for R\&D input. Following a line of argument similar to Katz, we presume an increase in research output leads to increased social welfare.

We assume the potential for R\&D spillovers is likely to be greatest among firms that are working in the same broadly defined technological areas. To measure this, we construct an index of firms' proximity in technology space. While this helps us measure spillover potential, we think it is plausible that the degree of R\&D spillovers actually realized within a consortium may be affected by the organizational structure of the consortium, and we will include quantitative measures of various aspects of this organizational structure in our empirical specifications.

(1989), and Kamien and Zang (2000), suggests that this kind of spillover expands the range of equilibria under which consortia are welfare enhancing. 
We measure the degree of ex-post product market competition among participating firms along multiple dimensions. We create a quantitative index of "proximity" of our participating firms in the product space, based on the degree of overlap in their product portfolios. However, when $\mathrm{R} \& \mathrm{D}$ consortia focus on basic $\mathrm{R} \& \mathrm{D}$, the technological focus of the consortium is far removed from commercialization. It is unlikely that the success of such a consortium would immediately lead to more intense product market competition - even if the participating firms are quite proximate in terms of their current product portfolios. In this case, the effective level of product market competition could be quite low. To capture this dimension of "proximity," we include a quantitative measure of the "basicness" of research conducted within a consortium. In order to get still another measure of the product market proximity of participating firms, we will also include a measure of the "diversity" of the "primary industries" of these participating firms.

In investigating the impact of these consortium characteristics on consortium outcomes, we confront a number of empirical challenges. Among the most serious is the problem of sample selection. As noted by Klette, Moen and Griliches (2000), this is probably the single greatest econometric problem facing any paper seeking to measure the impact of government support on commercial R\&D activity. This problem is present in our study because Japanese government officials encouraged firms with strong R\&D programs to participate in their consortia. ${ }^{6}$ However, our data set allows us an unusual degree of empirical leverage concerning this problem. Because we observe patenting in the targeted technologies by individual firms before, during, and after participation in a consortium, we are able to control for pre-existing technological strength in the targeted technologies. Because our data set includes observations

\footnotetext{
${ }^{6}$ Some projects provide an interesting exception to this general rule. These are projects that were organized in response to political pressure to extend government support to a declining industry. For these projects, the sample
} 
on firms that did not participate in consortia, we can take a "difference-in-differences" approach to the measurement of consortium impact. Finally, because we observe the same firms participating in multiple consortia, we are able to measure the marginal impact of different consortium characteristics on research outcomes, controlling for firm and consortium fixed effects.

\section{3. $R \& D$ consortia in $\mathbf{J a p a n}^{7}$}

The empirical analysis in this paper uses data on all company-to-company cooperative R\&D projects formed with a degree of government involvement from 1980 through $1992 .^{8}$ This data set was collected from each ministry through direct contacts after examining a wide range of government white papers and other government publications, and is as close as possible to an exhaustive list of all the government-sponsored R\&D consortia in Japan during that time period. ${ }^{9}$

In general, Japanese R\&D consortia involved some government subsidization of consortia R\&D expenditures, lowering the effective cost of R\&D. Secondly, the government generally sought (not always successfully) to encourage complete dissemination of all research results to the participating firms. Furthermore, in selecting participants for consortia formed since the early 1980s, the government generally sought to bring together firms with complementary research assets. ${ }^{10}$ This implies the level of intra-consortium spillover could be quite high. Consortia often brought together firms that were not direct rivals in the product market, and they

selection bias works in a direction similar to that of the famous "Ashenfelter dip" in the labor economics literature (Ashenfelter, 1978).

${ }_{8}^{7}$ We note that this section draws heavily from Branstetter and Sakakibara (1998).

8 This sample includes cooperative R\&D projects sponsored by the Ministry of International Trade and Industry (MITI), the Ministry of Transportation, the Ministry of Agriculture, Forestry and Fisheries, the Ministry of Post and Telecommunications, and the Ministry of Health and Welfare.

9 The data on consortia were originally prepared for Can Japan Compete?, by Michael E. Porter, Hirotaka Takeuchi, and Mariko Sakakibara (2000). For further details on construction of these data, see Sakakibara (1997a,b). 
often targeted markets where Japanese firms played a small role in global production and trade. Both factors worked to minimize the potential negative effects of $R \& D$ consortia on industry profits. Finally, prior to 1990 , many if not most of the patents that directly emerged from the research undertaken within government-sponsored research consortia were, by government directive, assigned not to the participating firms but to the research consortia themselves. ${ }^{11}$ We obtained data on the patents assigned to these consortia as well as those assigned to participants.

\section{Estimating the overall time path of benefits from research consortia}

Measurement of consortium outcomes. Before investigating the relationship between consortium characteristics and consortium outcomes, we first identify the overall impact of research consortia on participating firms' research output and the time path of that impact. In Katz's model, the only "output" of a successful R\&D project is a reduction in the marginal production costs of firms. ${ }^{12}$ Because of the long, variable lags involved in converting a research advance into a process improvement (or a new product), it is practically impossible to measure the effect of $R \& D$ consortia on marginal cost with any degree of accuracy, particularly when the participating firms are large, multi-product firms and the consortia each target only a small part of the firms' product/technology portfolios.

Patents provide a more direct and easily measured index of the innovative output associated with research consortia. We assume Japanese firms patent a fraction of their economically useful innovations, though this fraction can be allowed to vary across firms and

\footnotetext{
${ }^{10}$ Our analysis focuses on consortia formed between 1980 and 1992.

11 This policy clearly creates both a moral hazard problem and a measurement problem. We consider both in subsequent sections of the paper.

12 Following Spence (1984), if one thinks of a product as the services it delivers to the consumer, and R\&D reduces the cost of delivering those services, then "product-innovation" R\&D could be modeled in the same way as "costreducing" R\&D.
} 
industries. Provided this assumption is correct, the ultimate impact of a consortium on its members' innovation can be measured by looking at the increase in patenting in the targeted technologies registered by the participating firms during and after the consortium. ${ }^{13}$ While we cannot directly measure the impact of this R\&D output on social welfare, we will assume - as Katz does - that social welfare increases when the level of R\&D output goes up.

Data. ${ }^{14}$ For every consortium, we know which firms participated, the total R\&D budget of the consortium, the government's contribution, the consortium's duration, and its technological goals. With the aid of the Japanese Patent Office, we have been able to construct a mapping from the description of the consortium goals in the official program documentation to codes or groups of codes in the International Patent Classification system. This mapping allows us to measure the patenting of consortium firms in the targeted technologies. ${ }^{15}$ When we aggregate across participating firms within a consortium, such that the consortium itself is the unit of analysis, we can add to our output measure the patents taken out in the name of the consortium itself.

In addition to information on firms' patenting in the targeted classes in Japan, we have also constructed measures of firms' patenting in the targeted classes in the United States. Having this alternative patent series provides us with a useful robustness check. In taking out a patent in the United States, a Japanese firm has to translate the patent application and reformat it in a way that conforms to the very different requirements and procedures of the U.S. patent system.

\footnotetext{
13 There are obvious issues of causal inference that later sections will address.

14 Data sources are discussed in the Data Appendix.

15 It is important to point out that our mapping from the technological goals of a consortium to the related patent classes almost certainly captures innovations that were related to but not necessarily part of the actual goals of the consortium. This is useful in that it allows participation in a consortium to have a positive impact on R\&D in related fields. It is potentially problematic in that it may systematically overstate the actual innovative output resulting from a given consortium. However, if we find an increase in patenting in the classes related to a consortium at precisely
} 
Interviews with Japanese firms and empirical evidence suggest Japanese firms will only go through this additional trouble for the ideas that they perceive, at least ex ante, to have the most promise. ${ }^{16}$ Thus, the U.S. patent series provide us with a "quality-adjusted" stream of patents. ${ }^{17}$

Sample statistics of the data used for our empirical analyses are presented in Table 1. This gives data on the cross-section of consortia. ${ }^{18}$ Matching the consortium data to firm-level data yields usable data on about 145 consortia. As the standard deviations for each variable make clear, there is substantial heterogeneity across consortia in terms of the mix of participants, their pre-existing technological strengths in the targeted areas, and the total resources expended on the consortium. Data on R\&D spending, patenting, and most other variables for participating firms are available from 1980 through 1994.

Table 1 about here

Overall time path of impact. If R\&D consortia were "successful," in that they stimulated or enhanced research productivity, then, controlling for research inputs and preexisiting technological strength, we should observe a consortium-induced increase in patenting in the targeted area. However, unless we can compare ex-post trends in the patenting of participating firms to those of similar firms that did not participate, it is difficult to get around the sample-selection problem identified in section 2. Fortunately, our data set allows us to break up

the time a consortium is being undertaken, then it is likely that this increase may be driven — at least in part — by the consortium.

${ }^{16}$ Furthermore, whereas our Japanese data are based on patent applications, our U.S. data are based on patent grants (dated by year of application) - that is, applications which have been judged by the U.S. patent office to be sufficiently innovative to merit a patent grant.

17 Henderson and Cockburn (1996) have also used patents taken out in multiple countries as a "quality-adjusted" measure of innovative output. An alternative approach would be to filter our U.S. patent data further by using information on the ex-post citations of these patent grants. Creating such a measure of innovative output is the subject of ongoing research efforts. 
the individual consortia into the participating firms. For most consortia, these participating firms can be matched to a broadly comparable set of nonparticipants. This disaggregation allows us, at least in principle, to take a "difference-in-differences" approach to the data.

Along with these advantages of disaggregation come two very important disadvantages. First, we cannot apportion the patents taken out in the name of the consortium to the individual firms, which means we cannot fully capture the innovative output of consortia at this level. Second, we do not have perfect information on how government subsidies or the participating firms' total private contributions to the consortium research effort were divided across firms and years. This means firms' R\&D inputs are, at best, measured with considerable error. Because these measurement problems are slightly less problematic when one aggregates across the firms in a given consortium, we also experimented with regression analysis at the consortium level of aggregation. ${ }^{19}$ Some results from this level of aggregation will be presented in this paper, for comparison purposes.

To estimate the consortium-induced increase, if any, on innovative output, we take the participation of firm $i$ in consortium $j$ as the unit of analysis, and we count all the patents taken out in the targeted area(s) by each participating firm in the years prior to, during, and after the joint research project undertaken by the consortium. ${ }^{20}$ The estimating equation becomes:

$$
\begin{aligned}
& P_{i j t}=\alpha_{0}+\beta_{0} \text { dlag } 0+\beta_{1} \text { dlag } 1+\beta_{2} \text { dlag } 2+\beta_{3} \text { dlag } 3 \\
& +\beta_{4} d \operatorname{lag} 4+\beta_{5} d \operatorname{lag} 5+\beta_{6} \operatorname{dlag} 6+\beta_{7} d \operatorname{lag} 7+\beta_{8} d \operatorname{lag} 8 \\
& +\beta_{9} \text { dlag } 9+\beta_{10} \text { dlag } 10+\beta_{11} \text { dlag } 11+\beta_{12}{\text { dlag } 12+\chi R_{\text {Real }} \text { budget }_{i j t}} \\
& +\lambda \text { Pre }_{\text {project_patent }}+\text { preal_indirect_inputs }_{i j t}+\varepsilon_{i j t}
\end{aligned}
$$

\footnotetext{
18 We emphasize that these sample statistics are drawn from only one of several alternative "cuts" of the data employed in this paper.

19 For a further discussion of these R\&D measurement issues, see the Data Appendix and Branstetter and Sakakibara (2000). This paper also reports the results of an extensive set of consortium-level regressions.

20 We thank Adam Jaffe for this suggestion.
} 
$P_{i j t}$ denotes the patents generated by firm $i$ in consortium $j$ in year $t$ in the technological areas targeted by that consortium. $P_{i j t}$ is given as a simple count. ${ }^{21}$ Real_budget $t_{i j t}$ represents our estimate of the total research resources — private funds and public subsidies — expended by firm $i$ in consortium $j$ in year $t$ on the technologies targeted by that consortium. Unless otherwise specified, this variable and all other measures of research inputs are measured in logs, in order to obtain regression coefficients with an elasticity interpretation. Pre project_patent ${ }_{i j}$ denotes the average patenting by firm $i$ in the technology classes targeted by consortium $j$ prior to the start of that consortium, with the average taken over a 5-year window prior to the official start date of the consortium. This variable is included to control for the pre-existing technological strengths of consortium participants in the targeted classes. Real_indirect_inputs $s_{i j t}$ gives our best estimate of the resources that may have "seeped in" to the inputs of firm $i$ as a consequence of its participation in overlapping consortia (that is, other consortia whose technological goals overlap with those of consortium $j$ ) in year $t^{22}$ Note that here, and throughout the paper, $t$ is measured with respect to the inception of consortium $j$, rather than "calendar time."

An skeptical view of research consortia would be that any positive impact on the innovative output of participating firms is produced entirely by the resources, public and private, expended on the project. A more positive view would maintain that, in addition to the financial resources, the process of bringing firms with complementary research assets into contact should itself enhance the innovative activity of the firms. If we find an increase in research output that remains even after controlling for consortium-related increases in $R \& D$ inputs, then this would

\footnotetext{
${ }^{21}$ In estimating linear regression models, we add "1" to each observation, then take the log to avoid the problem of taking the log of zero. This transformation is standard in the $\mathrm{R} \& \mathrm{D} /$ productivity literature. Regressions using count data models yield qualitatively similar results. These results and other additional results whose tables are not presented here are reported in Branstetter and Sakakibara (2000).

${ }^{22}$ Issues regarding the measurement of these indirect inputs are discussed further in the Data Appendix.
} 
constitute evidence that consortia actually enhance research productivity. We test for such an increase by estimating a set of dummy variables to capture the change in patenting associated with the individual years after the inception of the consortium. For instance, in our basic specification, dlag0 represents a dummy variable that takes a value of 1 in the year of the inception of the consortium, and 0 otherwise. Other dummy variables, dlag1 through dlag12, correspond to lags of set length after the inception of the consortium. ${ }^{23}$

A more complete exploitation of the information provided by our "control" (that is, nonparticipating) firms would require a modification to equation (1). Consider the following slightly more complicated specification:

$$
\begin{aligned}
& P_{i j t}=\alpha_{0}+\beta_{0} \operatorname{dlag} 0+\beta_{1} \operatorname{dlag} 1+\beta_{2} \operatorname{dlag} 2+\beta_{3} \operatorname{dlag} 3+\beta_{4} \operatorname{dlag} 4+\beta_{5} \operatorname{dlag} 5 \\
& +\beta_{6} \text { dlag } 6+\beta_{7} \text { dlag } 7+\beta_{8} \text { dlag } 8+\beta_{9} \text { dlag } 9+\beta_{10} \text { dlag } 10+\beta_{11} \text { dlag } 11+\beta_{12} \text { dlag } 12 \\
& +\delta_{0} \operatorname{deff} 0+\delta_{1} \operatorname{deff} 1+\delta_{2} \operatorname{deff} 2+\delta_{3} \operatorname{deff} 3+\delta_{4} \operatorname{deff} 4+\delta_{5} \operatorname{deff} 5+\delta_{6} \operatorname{deff} 6 \\
& +\delta_{7} \operatorname{deff} 7+\delta_{8} \operatorname{deff} 8+\delta_{9} \operatorname{deff} 9+\delta_{10} \operatorname{deff} 10+\delta_{11} \text { deff } 11+\delta_{12} \operatorname{deff} 12 \\
& +\chi \text { Real_budget }_{i j t}+\lambda \text { Pre }_{-} \text {project_patent }_{i j}+\gamma \text { Real_indirect_inputs }_{i j t}+\varepsilon_{i j t}
\end{aligned}
$$

Here, we are estimating two "time paths." The first set of dummy variables, dlag0 through dlag12, captures the changes over time in patenting in the targeted technologies that are common to Japan's technologically elite firms, both participants and nonparticipants. ${ }^{24}$ If consortia are only created in "hot" technological areas, in which there would have been an increase in patenting even in the absence of the consortia, then this first set of dummy variables will capture that effect. The second set of dummy variables, deffo through deff12, captures those changes that are unique to participating firms. If these dummy variables are significantly different than zero,

\footnotetext{
${ }^{23}$ Consortium duration in our sample runs from 1 to 13 years, with half of all consortia ending four to eight years after the official inception.

${ }^{24}$ Sample firms were pre-selected on the availability of R\&D data and patent data in both Japan and the United States. Obviously, we oversample R\&D-intensive firms, hence our characterization of both the participants and the control sample as "technologically elite" firms.
} 
then that would suggest participation in consortia has a positive impact on the research outcomes of participating firms.

Table 2 and Figures 1 and 2 about here

Results at the firm-consortium level. For comparison purposes, column 1 of Table 2 provides the results of a regression of specification (1) on data aggregated up to the consortium level. Column 1 reports results from a linear specification, using the log of counts of Japanese patent applications in the targeted areas as the dependent variable. These results are graphed out in Figure 1, which plots the coefficients on our time dummy variables against the years to which they correspond, along with the $95 \%$ confidence bounds.

In contrast, columns 2 and 3 of Table 2 present the results from specification (2) on data at the firm-consortium level. Note that, in these columns, we regard firm i's participation in consortium $j$ as a separate event from firm $i$ 's participation in consortium $k$. We regress patenting on inputs, pre-existing technological strength (calculated for the individual firms), and the two sets of dummy variables described above. Columns 2 and 3 are taken from a Negative Binomial specification, which uses counts of Japanese patent applications in the targeted area as the dependent variable. The coefficients in Column 3 measure the performance of the participants relative to the "benchmark" level of performance common to both participants and controls, and these coefficients are graphed out in Figure 2, along with the $95 \%$ confidence bounds. 
Briefly summarized, these results suggest that both participants and nonparticipants tend to increase their patenting in the targeted technologies after the inception of a consortium. ${ }^{25}$ However, the marginal increase of participants' patenting in the targeted area, relative to the control firms, is large and statistically significant. ${ }^{26}$ The shape of this marginal effect on innovative output is also interesting. On average, this marginal impact tends to level off or decline in magnitude and lose statistical significance in the 4th to 8th year after the consortium's inception, increasing substantially thereafter. This is the point around which the average consortium's official duration is ending.

Why does Japanese patenting in the targeted area by the participating firms level off even begin to decline - as most consortia are ending, then increase substantially thereafter? We suspect the reason is strongly linked to the requirement, which held for many of the consortia we looked at, that patents taken out directly as a function of consortium research were to be assigned to the consortium, preventing the firm from fully appropriating the benefits of its research within the consortium. Given this restriction, there was obviously an incentive to delay patenting useful discoveries until after the consortium officially ended. The time path of benefits is quite consistent with the view that this "moral hazard" problem existed, and that firms behaved in an opportunistic manner. $^{27}$

\footnotetext{
25 This could be interpreted as evidence of "spillovers" of the results of consortia research to technologically active non-participants.

${ }^{26}$ Linear and Negative Binomial models using U.S. patents as the dependent variable and incorporating a "calendar time" trend yielded qualitatively similar results.

27 These results are also consistent with the view that the knowledge obtained through the consortia was incorporated in the firms' own research programs after the official ending of the joint research programs, and after the consortia each firm conducted substantial research in the consortia-related area. In some specifications, we included a separate dummy variable, which indicated the end of individual projects. This dummy variable was negative, suggesting a decline in output in the final year of the project. We also examined dummy variables corresponding to the first 3 years prior to the inception of a project, to see if projects generally began after the participating firms had already begun increasing their patenting in the targeted area. In many cases, these dummy variables were not statistically distinguishable from zero. In other cases, these dummy variables were positive, but
} 
Our approach would more closely approximate the "difference-in-differences" studies undertaken in the labor economics literature if we included firm and consortium fixed effects. Unfortunately, the inclusion of fixed effects makes it difficult to estimate two statistically distinct time paths. However, it is possible to estimate a fixed effects model using a more "parametric" approach to the estimation of the "time path of benefits." 28 We can construct for each firmconsortium-year observation (both participating firms and controls) a dummy variable corresponding to 1 during the official duration of the consortium (zero otherwise), a time trend which dates from the inception of consortium $j$, and the square of this time trend. Then we estimate another dummy variable equal to 1 during the duration of the consortium only if firm $i$ is a participant in consortium $j$, zero otherwise. Similarly, we construct the time trend and its square where these variables are nonzero only if firm $i$ is a participant in consortium $j$. This allows us to trace out, albeit less precisely, the general shape of the time path of changes in patenting in the targeted area for all firms and then the impact of participation on the participating firms only relative to that baseline.

Results from such a specification suggest participating firms receive a statistically significant boost in performance over the level of nonparticipants that persists over time. ${ }^{29}$ However, the increase in performance is rather small in size (on the order of $5 \%$ using U.S. patents as the dependent variable). While the results given in Table 2 would seem to imply quite large and persistent positive effects, the specifications which most closely approximate a

their inclusion did not alter the finding of positive and significant increases in patenting after the inception of the project.

${ }_{28}$ In these specifications, the participation of firm $i$ in consortium $j$ was considered to be the cross-sectional unit. A fixed effect was incorporated for each such unit.

29 A complete set of results from a specification of this kind is reported in Branstetter and Sakakibara (2000). 
"differences-in-differences" treatment of the data suggest that this average impact is much more modest in size.

\section{Effects of consortium characteristics on consortium performance}

In this section, we turn our attention to the question of which consortia are more successful - and why. As we noted in section 2, the theoretical literature highlights two characteristics of an R\&D consortium as critical determinants of its impact: "spillover potential" of the consortium and the level of "product market competition" among consortium participants. So it is particularly incumbent upon us to come up with empirical measures of these characteristics. There are other characteristics that we wish to take into account as well, including the governance structure of consortia, their technological orientation (basic versus applied research), and the mix of participants in terms of industry affiliation.

In the empirical analysis in this section, we concentrate our attention on time-invariant characteristics of consortia. While equations (1) and (2) exploit the full panel structure of the data and give us insight into the important question of the time path of benefits, many of the variables on consortium characteristics that we have at the consortium level (or the firmconsortium level) do not change over time. Including them in a panel regression with a timeseries dimension actually creates statistical problems, as has been demonstrated by Moulton (1986). For that reason, it makes sense to collapse the time series dimension of the data. What we do henceforth is measure consortium outcomes as the cumulated sum of patenting in the targeted classes, taken over a fifteen year horizon (or as much of this as the data will allow) from the official inception of the consortium. This sum will be regressed on (summed) measures of 
research inputs, direct and indirect, measures of pre-consortium technological strength, and timeinvariant consortium characteristics.

Technological proximity of participants. If the potential for $R \& D$ spillovers is strongest among firms which are pursuing research in the same technological areas, then one needs a quantitative index of the proximity of firms in technology space ${ }^{30}$ Following Jaffe (1986), we employ such a measure, the $T_{i j}$ coefficient.

Let a firm's R\&D program be described by the vector F, where $F_{i}=\left(f_{1} \ldots f_{k}\right)$ and each of the $k$ elements of $F$ represents the firm's research resources and expertise in the $k$ th technological area. This is measured by the number of patents held by a firm in a narrowly defined technological field. We can measure the "technological proximity" between two firms by measuring the degree of similarity in their patent portfolios, or more precisely, the "distance" in "technology space" between two firms $i$ and $j$ can be approximated by $T_{i j}$ where $T_{i j}$ is the uncentered correlation coefficient of the $F$ vectors of the two firms:

$$
T_{i j}=\frac{F_{i} F_{j}^{\prime}}{\left[\left(F_{i} F_{i}^{\prime}\right)\left(F_{j} F_{j}^{\prime}\right)\right]^{1 / 2}}
$$

We calculate a technological proximity measure for each consortium for which we have sufficient data by averaging $T_{i j}$ for all pairs of firms in a consortium. ${ }^{31}$ A number close to 1 implies a high degree of technological proximity, while a number close to 0 implies a low degree of technological proximity.

\footnotetext{
30 However, it is certainly possible that there may be important technological complementarities between "distant" technologies that measures of "technological proximity" may fail to capture.

31 This calculation is made by using data on U.S. patents granted to Japanese consortia participants from 1980 through 1996, and follows Branstetter and Sakakibara (1998) and Branstetter (2000). Note that in many cases, we do not possess sufficient patent data to compute an $F$ vector for each participant. This inevitably introduces an extra element of measurement error into our $T_{i j}$ measures. Firms which are not included are, however, typically small, unlisted firms.
} 
For a subset of our firms and consortia for which we have sufficient data, we can calculate a separate technological proximity measure for each firm in each consortium by averaging the term defined in equation (3) over all firms $j$ not equal to $i$. This construction gives us a measure we can use in an econometric specification that includes firm and consortium fixed effects. $^{32}$

Product market proximity of participants. Our measure of product market proximity is calculated using data from Market Share in Japan (1984, 1990), which is published by the Yano Research Institute. This private Japanese market research firm tracks the market shares of the top Japanese firms in hundreds of narrowly defined product markets. ${ }^{33}$ We use these data to count the number of times a pair of firms in a given consortium "meet" each other in product markets. For each firm, a proximity measure with respect to each other firm can be calculated by dividing the number of product markets in which a meeting takes place by the number of product markets in which firm $i$ is currently active. Two firms which meet one another in a large number of product markets are presumed to be more proximate to one another than firms for whom the set of overlapping products is small or zero.

However, our measure of proximity does not guarantee symmetry. For any pair of firms, $i$ may be closer to $j$ than $j$ is to $i$ if $i$ is in only one product market (and meets $j$ in that market) whereas $j$ is in one hundred product markets, in only one of which it meets $i$. For $i, j$ is a major and close competitor, while for $j, i$ 's presence is negligible. This measure captures the asymmetries of product market competition that exist in the real world between multi-product

\footnotetext{
${ }^{32}$ We thank an anonymous referee for suggesting this approach.

33 The data used in this paper track firm meetings in 591 distinct, disaggregated product markets. For some product markets, this data source actually includes sales figures for individual years. Unfortunately, sales data are not recorded for all product markets, making it impossible to construct an index of product market proximity based on revenue figures.
} 
and single-product firms of very different sizes. As in the case of our "technological proximity" measures, we calculate product market proximity in two ways — averaging over all firms within a consortium to produce a consortium-specific measure and averaging within firms and consortia to produce a firm-consortium specific measure. The latter can be used in an econometric specification with firm and consortium fixed effects. ${ }^{34}$

Basic technological orientation. For a subset of firms and consortia in our database, we have a rich set of qualitative variables recording Japanese R\&D managers' perceptions of various aspects of the consortia. ${ }^{35}$ These variables were obtained from a survey conducted by Sakakibara (1994, 1997a,b). Among the most interesting and relevant of these survey responses are those pertaining to the nature of the technological goals of the joint research projects undertaken by the consortia. While obviously highly subjective, the respondents' answers to the following questions nevertheless provide quite useful information on the technological "ambitiousness" and technological "focus" of the project. Questions include the following: 1) Rank the project outcomes along a spectrum from basic to highly applied research. 2) How ambitious was the goal of the project? 3) What was the state of development of the subject industry? The respondents' answers to these questions were recorded on a 5-point Likert scale. These responses were then averaged for participants in the same project. Because a number of these variables measure similar factors, there are potential problems of multicollinearity and interpretation. What works better empirically is to collapse a number of variables into a simple linear combination of the variables that serves as a univariate summary statistic of the "basicness" of research conducted in the consortium, with a larger index indicating that the consortium targeted more basic research.

\footnotetext{
${ }^{34}$ We thank an anonymous referee for suggesting that we move in this direction.
} 
As discussed in section 2, when R\&D consortia focus on basic R\&D, the effective level of ex-post product market competition could be quite low, even if the participants are quite proximate, in terms of their current product portfolios. With these data, we can measure "product market competition" along both dimensions stressed in the theoretical literature.

Centralization of consortium organization. A separate set of survey questions dealt with the management structure of the joint research project undertaken by the consortia. Questions asked on this topic include the following: 1) Was there a central research laboratory for the project? 2) To what extent was the consortium research undertaken "centrally" versus research performed separately by individual companies? 3) How often did researchers from different companies meet? 4) To what extent did the consortium administrators try to keep the project under "tight" control? As with the other set of survey variables, we aggregated a number of these into a single univariate measure of the "centralization" of research, with a larger index indicating that the project was implemented in a more centralized manner.

Industry mix / wide participation. A third set of survey questions dealt with the "participation pattern" of firms in the consortia. This provides useful information on the "inclusiveness" of the consortium, such as the presence of firms from upstream/downstream industries. Questions include the following: 1) How wide was participation in your principal industry? 2) Did the technology leader in your industry participate? 3) How wide was participation from other industries? 4) Did upstream or downstream industries participate? The aggregated single univariate measure is constructed such that the larger the index, the greater the diversity in terms of the industry mix of participating firms.

35 This data covers 86 projects that had ended or were close to completion in 1992. 
Results at the firm-consortium level. The impact of consortium characteristics on consortium outcomes could be measured at a number of different levels of aggregation. For instance, we can use the consortium itself as the unit of analysis. ${ }^{36}$ While interesting and potentially informative, the consortium-level regressions are subject to a serious identification problem. We would like to interpret the coefficients on the characteristics of our consortia as giving us the marginal effect of a unit change in a given consortium characteristic on the outcome of a consortium. The problem with this interpretation is that the coefficients on our consortium characteristics could be reflecting differences in the participating firms across consortia as much as they reflect the "ceteris paribus" marginal impact of a unit change in a given consortium characteristic.

In order to address this issue, we utilize our "firm-consortium" cut of the data. We can collapse the time dimension of this data set, summing up measures of patent output and R\&D input over a fixed horizon beginning with the inception of the consortium. However, even after collapsing the time dimension, we are left with two other dimensions to our data set - the project, or consortium, dimension, and the firm dimension. This gives us critical leverage around the problem in the preceding paragraph.

Ideally we would like to conduct the following conceptual experiment: to examine how the same firm would perform if, for example, we moved it from a consortium with a low level of average technological proximity to one with a high level of average technological proximity. Since we observe the same firms in a number of different consortia, a regression on our "firmconsortium" panel data set with firm fixed effects allows us get close to this ideal experiment.

\footnotetext{
${ }^{36}$ Branstetter and Sakakibara (2000) report a full set of regression results of outcomes on consortium characteristics using the consortium itself as the unit of analysis.
} 
Holding the unobserved characteristics of individual firms constant, we can trace out the average marginal impact of differences in consortium characteristics on research outcomes. ${ }^{37}$

We would get even closer to this ideal experiment if we could also include consortium fixed effects. Our measured consortia characteristics could potentially be correlated with unmeasured characteristics of those same consortia. Employing consortium fixed effects provides us with empirical leverage concerning this issue, at least in principle. The practical problem with including consortium fixed effects is that any characteristic that is the same across all firms in a given consortium "falls out" with the fixed effect. Unfortunately, some of our consortium characteristics are not available at the firm-consortium level, but only at the consortium level, and we are thus constrained from including consortium fixed effects in some specifications.

Given these constraints, there are two ways of measuring the consortium-induced boost to firm patenting in the targeted patent classes in these data. One way is to regress the cumulated sum of patenting in the targeted area on inputs, pre-project patenting, consortium characteristics, firm fixed effects, and, in some cases, consortium fixed effects. This approach is illustrated in the following equation for firm $i$ in consortium $j$ :

$$
\begin{aligned}
& P_{i j}=\alpha_{0}+\chi \text { Real_budget }_{i j}+\lambda \text { Pre_project_patent } \\
& i j \\
& +\mu \text { Rechnological_proximity }_{i j}+\kappa \text { Product_markect_input }_{i j} \\
& \text { Prot }_{-} \text {proximity }_{i j}+\theta_{i}+\varepsilon_{i j}
\end{aligned}
$$

where $\theta_{i}$ is a firm fixed effect. Alternatively, we subtract a cumulated sum of pre-project patenting from the output measure, and use this difference (or in our case, the difference of the $\operatorname{logs}$ ) as the dependent variable. Table 3 takes both approaches to the estimation of the impact of technological and product market proximity on outcomes.

37 The specifications reported in Tables 3 and 4 do not include control firms. Similar specifications which included 
For comparison purposes, column 1 of Table 3 presents results from a Negative Binomial model estimated at the consortium level of aggregation. At this level of aggregation, it is impossible to include either firm or consortium fixed effects. Furthermore, measures of technological proximity and product market proximity are averaged across participating firms within a consortium. Nevertheless, we find that technological proximity and product market proximity have the predicted effects on consortium outcomes. The former is significantly positive in its effects, while the latter is significantly negative.

In column 2, we move our analysis to the firm-consortium level. However, we continue to use measures of technological and product market proximity that are consortium specific rather than firm-consortium specific. We take the linear "levels" approach suggested in equation (4), incorporating firm (but not consortium) fixed effects. ${ }^{38}$ Taking a slightly different approach, column 3 presents results from the "differences" specification, where the dependent variable is the difference in the (log) patent output in the targeted area before and after the inception of the consortium. In column 3, U.S. patents in the targeted area, rather than Japanese patents, are used as indicators of innovative output. Columns 2 and 3 illustrate that the estimated effects of our two key consortium characteristics still have the predicted signs and are still statistically significant. ${ }^{39}$

For all the reasons discussed above, an even more stringent test of our hypotheses would be to insert firm-consortium specific measures of technological and product market proximity into a specification with both firm and consortium effects. When we construct these firmconsortium specific measures, we lose a number of observations, because we lack sufficient data

control firms were tested and yielded qualitatively similar results.

${ }^{38}$ Attempts to estimate a fixed effects negative binomial estimator with these data failed to achieve convergence. 
to compute these measures for all firms in all projects. Furthermore, including firm effects and consortium effects absorbs a very large portion of the total variance in our outcomes data. Given the loss of observations we incur in taking this approach and the loss of variance we incur by including firm and consortium fixed effects, it would perhaps not be surprising if our econometric results lost some of their statistical precision.

Nevertheless, as can be seen from column 4 of Table 3, when we include firm fixed effects, consortium fixed effects, pre-project patenting, and measures of private and public R\&D input as independent variables, it is still the case that our measures of technological proximity are positive and statistically significant. On the other hand, our measures of product market proximity, though negative, are not statistically significant at conventional levels. ${ }^{40}$ We view the fact that our technological proximity measures survive this test and the product market proximity measures do not survive it as being essentially consistent with results reported in the next table, in which the impact of product market proximity is systematically less robust than that of technological proximity. Column 4 uses U.S. patents as its measure of innovative output, but we note that results obtained with Japanese patents are qualitatively similar. ${ }^{41}$

Tables 3 and 4 about here

39 The exception to this is that product market proximity is not statistically significant at the conventional levels in column 2 .

40 The way we measure direct R\&D inputs, they should be the same for all firms within a given consortium. However, there are some consortia for which we only have data on all independent variables for a single firm. For these consortia, a consortium fixed effect cannot be estimated from the data, though the impact of direct inputs can. Because of these single-firm consortia, we are able to identify a separate effect of the consortium R\&D budget on firm-consortium research output in column 4. The results shown, however, do not change qualitatively if we drop all "single-firm" consortia and re-estimate the specification using only the remaining consortia without a separate measure of direct inputs.

41 Results using Japanese patents as the measure of innovative output in a specification with firm and consortium fixed effects indicate that the impact of technological proximity is positive and statistically significant, whereas the impact of product market proximity is statistically indistinguishable from zero. However, we note that the results with Japanese patenting are not robust to the inclusion of pre-project patenting as a control. For further robustness tests, see Branstetter and Sakakibara (2000). 
Table 4 reports the results of regressions similar to those in Table 3, except that here we add measures of project "organizational characteristics" — basic research orientation, "centralization" of the consortium governance structure, and measures of "diversity" in terms of the industry affiliation of participating firms. Unfortunately, it is not possible to obtain firmconsortium specific measures of these characteristics. Recall that they were obtained from a limited survey of participating firms, and the number of firm responses within a given consortium is too small. For this reason, we use consortium-specific measures of these attributes — and that precludes the use of a consortium fixed effect.

The only "organizational" attribute with robust effects is the one for which the theoretical literature gives us a clear interpretation — the basic research orientation of consortia. The more basic the research conducted within a consortium, the better the outcome. This is entirely consistent with theoretical predictions. Note that we do not possess measures of these organizational characteristics for all firms or all consortia. Our data set here is less than one-third the size of the data set used in Table 3, column 3, for instance. Given this loss of observations, it is not surprising that some of our measured characteristics lose statistical significance. The impact of product market proximity switches sign (relative to what we found in Table 3), but is statistically indistinguishable from zero.

One final observation merits mention here. In a number of specifications in Tables 3 and 4, the regression coefficients on our measures of $R \& D$ inputs to consortia are quite small in magnitude and in statistical significance. ${ }^{42}$ One interpretation of this is that the design of a consortium matters much more than the level of resources expended on it. Putting more money into a consortium in which the members have little prospect for technological spillover, little 
incentive to cooperate given their overlap in the product market, and little pre-existing technological strength in the targeted technologies will not help matters much. Likewise, a welldesigned consortium may have beneficial effects even if the direct subsidies expended are modest. $^{43}$

\section{Conclusions}

In this paper, we come closer than anyone else has to actually testing the propositions of Katz (1986) and others concerning the impact of research consortia. We find strong evidence that spillover potential, as measured by our technological proximity variable, is positively related to the outcomes of consortia, which is consistent with the predictions of much of the theoretical literature. We also find evidence that research consortia are likely to have a stronger positive impact when they conduct relatively basic, rather than relatively applied R\&D. Our evidence concerning the impact of the degree of product market competition is generally consistent with theoretical predictions, though these results are less statistically robust. Another consistent regularity in our empirical findings is that the design of a consortium seems to be more important than the level of resources expended on it in terms of explaining research outcomes. Taken together, these results suggest to us that the strategic reactions of firms to consortium attributes identified in the theoretical literature are empirically important in practice. This is a lesson that can and should be incorporated into public policy.

Our results suggest what kinds of consortia are likely to yield the highest returns on both public and private investments and how these benefits unfold over time. The empirical framework in the paper is one that could be applied to research consortia in any country. It is our

\footnotetext{
${ }^{42}$ Note that the measured impact of R\&D inputs also tends to be small in the specifications reported in Table 2.
} 
hope that this paper will stimulate such evaluative work. Partly as a result of economists' theoretical arguments, governments and firms around the world have invested billions in research consortia. Our profession would be remiss if we did not provide some way of evaluating the impact of this investment.

${ }^{43}$ An alternative explanation is that the small coefficients are primarily driven by measurement error in our R\&D data. 


\section{Figure 1. Time Path of Benefits}

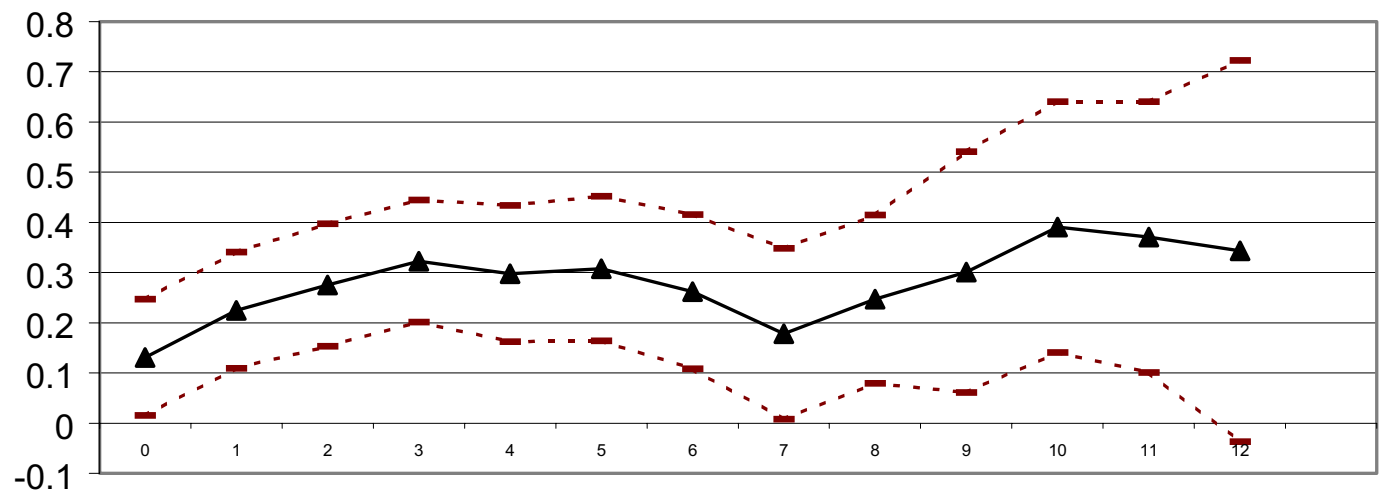

\section{Years Since Inception of Project}

Source: Table 2, column 1's coefficients of consortium year dummies and the $95 \%$ confidence bounds. These results are taken from the consortium level of aggregation.

Figure 2. Relative Performance of Participants

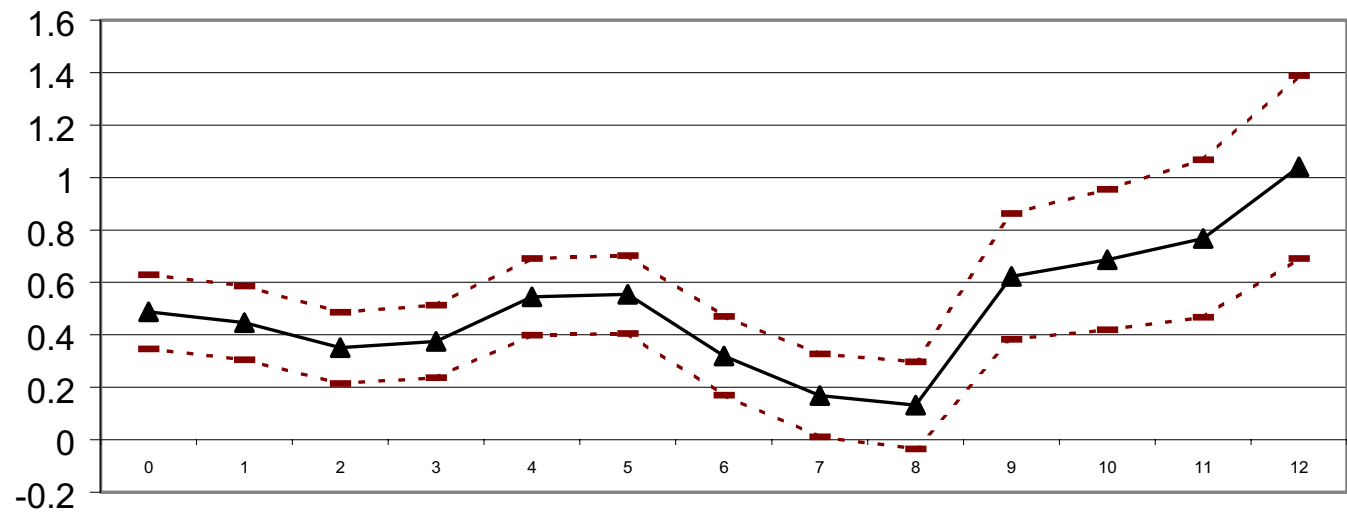

Years Since Inception of Project

Source: Table 2, column 3's coefficients of consortium year dummies for participants and the 95\% confidence bounds. These results are taken from the firm-consortium level of aggregation. 
Table 1. Summary Statistics

\begin{tabular}{|c|c|c|c|c|c|c|}
\hline Variable name & Description & $\begin{array}{l}\text { \# of } \\
\text { obs. }\end{array}$ & Mean & $\begin{array}{l}\text { Std. } \\
\text { Dev. }\end{array}$ & Min & Max \\
\hline Project Patenting & $\begin{array}{l}\text { \# of patent applications by } \\
\text { consortium } i \text { and member firms in the } \\
\text { targeted technology class }\end{array}$ & 178 & 12,750 & 28,604 & 0 & 151,871 \\
\hline Total patents & $\begin{array}{l}\text { \# of patent applications by all firms in } \\
\text { Japan in the targeted technology class }\end{array}$ & 178 & 54,589 & 76,063 & 218 & 313,486 \\
\hline Total US patents & $\begin{array}{l}\text { \# of U.S. patent grants in targeted } \\
\text { classes }\end{array}$ & 178 & 333.7 & 720.2 & 0 & 4,265 \\
\hline Real budget & $\begin{array}{l}\text { Total consortia budget for consortium } \\
i \text { in } 1990 \text { million yen }\end{array}$ & 178 & 9,553 & 22,657 & 131 & 264,753 \\
\hline $\begin{array}{l}\text { Pre-project } \\
\text { patents }\end{array}$ & $\begin{array}{l}5 \text {-year average patenting in the } \\
\text { targeted classes by consortium } i \\
\text { participants prior to the start of a } \\
\text { consortium }\end{array}$ & 171 & 1,208 & 2,477 & 0 & 14,855 \\
\hline $\begin{array}{l}\text { Real indirect } \\
\text { inputs }\end{array}$ & $\begin{array}{l}\text { Inputs to consortium } i \text { spilling over } \\
\text { from other overlapping consortia, in } \\
1990 \text { million Yen }\end{array}$ & 178 & 18,059 & 31,372 & 0 & 184,223 \\
\hline $\begin{array}{l}\text { Starting year of } \\
\text { project }\end{array}$ & & 178 & 86.3 & 3.56 & 80 & 92 \\
\hline $\begin{array}{l}\text { Technological } \\
\text { proximity }\end{array}$ & $\begin{array}{l}\text { Distance in technological space } \\
\text { between two firms, averaged for all } \\
\text { pairs in consortium } i\end{array}$ & 156 & .473 & .211 & 0 & .981 \\
\hline $\begin{array}{l}\text { Product market } \\
\text { proximity }\end{array}$ & $\begin{array}{l}\text { \# of meetings between two firms in } \\
\text { product markets, divided by the } \\
\text { number of markets in which a firm is } \\
\text { active, averaged for all firms in } \\
\text { consortium } i\end{array}$ & 152 & .169 & .169 & 0 & .7702 \\
\hline $\begin{array}{l}\text { Basic } \\
\text { technological } \\
\text { Orientation }\end{array}$ & $\begin{array}{l}\text { Likert scale variable, averaged across } \\
\text { participants in consortium } i \text {, } \\
\text { measuring degree to which } \\
\text { consortium research was "basic } \\
\text { research" }\end{array}$ & 53 & 3.15 & .537 & 2 & 4.67 \\
\hline $\begin{array}{l}\text { Centralization of } \\
\text { organization }\end{array}$ & $\begin{array}{l}\text { Likert scale variable measuring } \\
\text { degree to which consortium research } \\
\text { was "centralized" }\end{array}$ & 53 & 2.54 & .634 & 1.5 & 4 \\
\hline Industry mix & $\begin{array}{l}\text { Likert scale variable measuring } \\
\text { degree of diversity in industry mix }\end{array}$ & 53 & 3.20 & .553 & 1.9 & 4.5 \\
\hline
\end{tabular}




\section{Table 2. Time Path of Benefits}

Dependent variable:

(1) Consortium patenting (assigned to firms and consortia) in the targeted area in year $\mathrm{t}$

(2) Firm patenting in the targeted area in year $t$

Standard errors in parentheses

\begin{tabular}{|c|c|c|c|}
\hline Variable & $\begin{array}{l}\text { (1)Linear } \\
\text { Model } \\
\text { (Consortium } \\
\text { level) }\end{array}$ & $\begin{array}{l}\text { (2) Negative } \\
\text { Binomial } \\
\text { Model (Firm- } \\
\text { consortium) }\end{array}$ & $\begin{array}{l}\text { Time } \\
\text { Coefficients for } \\
\text { Participants }\end{array}$ \\
\hline Year 0 dummy ${ }^{(a)}$ & $\begin{array}{l}.131 \\
(.058)\end{array}$ & $\begin{array}{l}.099 \\
(.065)\end{array}$ & $\begin{array}{l}.488 \\
(.071)\end{array}$ \\
\hline Year 1 dummy & $\begin{array}{l}.225 \\
(.058)\end{array}$ & $\begin{array}{l}.214 \\
(.064)\end{array}$ & $\begin{array}{l}.446 \\
(.070)\end{array}$ \\
\hline Year 2 dummy & $\begin{array}{l}.275 \\
(.061)\end{array}$ & $\begin{array}{l}.368 \\
(.062)\end{array}$ & $\begin{array}{l}.351 \\
(.068)\end{array}$ \\
\hline Year 3 dummy & $\begin{array}{l}.323 \\
(.061)\end{array}$ & $\begin{array}{l}.450 \\
(.064)\end{array}$ & $\begin{array}{l}.375 \\
(.069)\end{array}$ \\
\hline Year 4 dummy & $\begin{array}{l}.298 \\
(.068)\end{array}$ & $\begin{array}{l}.354 \\
(.068)\end{array}$ & $\begin{array}{l}.545 \\
(.073)\end{array}$ \\
\hline Year 5 dummy & $\begin{array}{l}.308 \\
(.072)\end{array}$ & $\begin{array}{l}.441 \\
(.069)\end{array}$ & $\begin{array}{l}.554 \\
(.074)\end{array}$ \\
\hline Year 6 dummy & $\begin{array}{l}.262 \\
(.077)\end{array}$ & $\begin{array}{l}.751 \\
(.070)\end{array}$ & $\begin{array}{l}.320 \\
(.075)\end{array}$ \\
\hline Year 7 dummy & $\begin{array}{l}.178 \\
(.085)\end{array}$ & $\begin{array}{l}.839 \\
(.074)\end{array}$ & $\begin{array}{l}.169 \\
(.079)\end{array}$ \\
\hline Year 8 dummy & $\begin{array}{l}.247 \\
(.084)\end{array}$ & $\begin{array}{l}.855 \\
(.077)\end{array}$ & $\begin{array}{l}.132 \\
(.083)\end{array}$ \\
\hline Year 9 dummy & $\begin{array}{l}.301 \\
(.120)\end{array}$ & $\begin{array}{l}.502 \\
(.108)\end{array}$ & $\begin{array}{l}.623 \\
(.120)\end{array}$ \\
\hline Year 10 dummy & $\begin{array}{l}.391 \\
(.125)\end{array}$ & $\begin{array}{l}.531 \\
(.121)\end{array}$ & $\begin{array}{l}.687 \\
(.134)\end{array}$ \\
\hline Year 11 dummy & $\begin{array}{l}.371 \\
(.135)\end{array}$ & $\begin{array}{l}.571 \\
(.135)\end{array}$ & $\begin{array}{l}.768 \\
(.150)\end{array}$ \\
\hline Year 12 dummy & $\begin{array}{l}.343 \\
(.190)\end{array}$ & $\begin{array}{l}.629 \\
(.156)\end{array}$ & $\begin{array}{l}1.04 \\
(.174)\end{array}$ \\
\hline Real budget & $\begin{array}{l}-.037 \\
(.019)\end{array}$ & $\begin{array}{l}.028 \\
(.006)\end{array}$ & \\
\hline Real indirect inputs & $\begin{array}{l}.031 \\
(.006)\end{array}$ & $\begin{array}{l}.036 \\
(.003)\end{array}$ & \\
\hline Pre-project patents & $\begin{array}{l}.926 \\
(.007)\end{array}$ & $\begin{array}{l}1.14 \\
(.004)\end{array}$ & \\
\hline Number of observations & 2,163 & 40,635 & \\
\hline
\end{tabular}

(a) Year 0 indicates the year of the inception of a consortium.

Note: Real budget, real indirect inputs, pre-project patenting, and dependent variables in linear models are measured in logs. 
Table 3. Technological Proximity and Product Market Proximity — Firm-Consortium

Level

Dependent variable:

(1) Consortium patenting in the targeted area

(2),(4) Sum of firm patenting in the targeted area

(3) The difference of firm patenting in the targeted area before and after inception of the consortium Standard errors in parentheses

\begin{tabular}{|c|c|c|c|c|}
\hline Variable & $\begin{array}{l}\text { (1) Negative } \\
\text { Binomial Model } \\
\text { (Consortium } \\
\text { Level) }\end{array}$ & $\begin{array}{l}\text { (2) Linear } \\
\text { Fixed Effects } \\
\text { Model - } \\
\text { Levels }\end{array}$ & $\begin{array}{l}\text { (3) Linear } \\
\text { Fixed Effects } \\
\text { Model - } \\
\text { Differences } \\
\text { (U.S. patents) }\end{array}$ & $\begin{array}{l}\text { (4) Linear Fixed Effects } \\
\text { Model - Levels (U.S. } \\
\text { patents, firm and } \\
\text { consortium fixed effects) }\end{array}$ \\
\hline $\begin{array}{l}\text { Technological } \\
\text { proximity } \\
\text { (consortium average) }\end{array}$ & $\begin{array}{l}.950 \\
(.260)\end{array}$ & $\begin{array}{l}.471 \\
(.188)\end{array}$ & $\begin{array}{l}.636 \\
(.110)\end{array}$ & \\
\hline $\begin{array}{l}\text { Product market } \\
\text { proximity } \\
\text { (consortium average) }\end{array}$ & $\begin{array}{l}-.625 \\
(.315)\end{array}$ & $\begin{array}{l}-.216 \\
(.270)\end{array}$ & $\begin{array}{l}-.474 \\
(.162)\end{array}$ & \\
\hline $\begin{array}{l}\text { Technological } \\
\text { proximity }\end{array}$ & & & & $\begin{array}{l}1.077 \\
(.317)\end{array}$ \\
\hline $\begin{array}{l}\text { Product market } \\
\text { proximity }\end{array}$ & & & & $\begin{array}{l}-.458 \\
(.398)\end{array}$ \\
\hline Real budget & $\begin{array}{l}.281 \\
(.044)\end{array}$ & $\begin{array}{l}.003 \\
(.002)\end{array}$ & $\begin{array}{l}.027 \\
(.007)\end{array}$ & $\begin{array}{l}-.154 \\
(.122)\end{array}$ \\
\hline Real indirect inputs & $\begin{array}{l}.010 \\
(.012)\end{array}$ & $\begin{array}{l}.033 \\
(.012)\end{array}$ & $\begin{array}{l}.017 \\
(.006)\end{array}$ & $\begin{array}{l}-.118 \\
(.073)\end{array}$ \\
\hline Firm's total R\&D & N.A. & $\begin{array}{l}.177 \\
(.014)\end{array}$ & $\begin{array}{l}.049 \\
(.006)\end{array}$ & $\begin{array}{l}.238 \\
(.245)\end{array}$ \\
\hline Firm fixed effects & No & Yes & Yes & Yes \\
\hline $\begin{array}{l}\text { Consortium fixed } \\
\text { effects }\end{array}$ & No & No & No & Yes \\
\hline $\begin{array}{l}\text { Number of } \\
\text { observations }\end{array}$ & 145 & 1,910 & 1,910 & 1,090 \\
\hline
\end{tabular}

Note: Real budget, real indirect inputs, firm's total R\&D, and dependent variables in linear models are measured in logs. Column 1 includes a measure of cumulative total patenting in the targeted area, and columns 1, 2, and 4 include levels of pre-project patenting. In column 3, levels of pre-project patenting are subtracted from the dependent variable. All columns include a measure of the starting year of the project, though these coefficients are not shown. 


\section{Table 4. Consortium Characteristics and Outcomes — Firm-Consortium Level}

Dependent variable: The difference of firm patenting in the targeted area before and after the inception of the consortium

Standard errors in parentheses

\begin{tabular}{|c|c|c|c|c|}
\hline Variables & $\begin{array}{l}\text { (1) Linear Fixed } \\
\text { Effects Model }\end{array}$ & $\begin{array}{l}\text { (2) Linear Fixed } \\
\text { Effects Model }\end{array}$ & $\begin{array}{l}\text { (3) Linear Fixed } \\
\text { Effects Model }\end{array}$ & $\begin{array}{l}\text { (3) Linear Fixed } \\
\text { Effects Model }\end{array}$ \\
\hline Technological proximity & $\begin{array}{l}1.26 \\
(.340)\end{array}$ & $\begin{array}{l}1.56 \\
(.350)\end{array}$ & $\begin{array}{l}1.40 \\
(.349)\end{array}$ & $\begin{array}{l}1.27 \\
(.342)\end{array}$ \\
\hline $\begin{array}{l}\text { Product market } \\
\text { proximity }\end{array}$ & $\begin{array}{l}.652 \\
(.491)\end{array}$ & $\begin{array}{l}.190 \\
(.504)\end{array}$ & $\begin{array}{l}.418 \\
(.505)\end{array}$ & $\begin{array}{l}.685 \\
(.494)\end{array}$ \\
\hline $\begin{array}{l}\text { Basic technological } \\
\text { orientation } \\
\text { (consortium average) }\end{array}$ & $\begin{array}{l}.604 \\
(.104)\end{array}$ & & & $\begin{array}{l}.534 \\
(.122)\end{array}$ \\
\hline $\begin{array}{l}\text { Centralization of } \\
\text { organization } \\
\text { (consortium average) }\end{array}$ & & $\begin{array}{l}.045 \\
(.079)\end{array}$ & & $\begin{array}{l}.088 \\
(.098)\end{array}$ \\
\hline $\begin{array}{l}\text { Industry mix / wide } \\
\text { participation } \\
\text { (consortium average) }\end{array}$ & & & $\begin{array}{l}-.279 \\
(.099)\end{array}$ & $\begin{array}{l}-.144 \\
(.136)\end{array}$ \\
\hline Firm fixed effects & Yes & Yes & Yes & Yes \\
\hline Number of observations & 531 & 531 & 531 & 531 \\
\hline
\end{tabular}

Note: Regressions included measures of real budget, real indirect inputs, and firm's total R\&D, though these coefficients are not shown in the table. These variables as well as dependent variables are measured in logs. Note that these models do not include consortium fixed effects. Measures of preproject patenting are subtracted from the dependent variable in these specifications. 


\section{References}

Ashenfelter, Orley. "Estimating the Effect of Training Programs on Earnings." Review of Economics and Statistics, February 1978, 60(1), pp. 47-57.

Branstetter, Lee. "Vertical Keiretsu and Knowledge Spillovers in Japanese Manufacturing: An Empirical Assessment." Journal of the Japanese and International Economies, June 2000, 14(2), pp. 73-104.

Branstetter, Lee and Sakakibara, Mariko. "Japanese Research Consortia: A Microeconometric Analysis of Industrial Policy.” Journal of Industrial Economics, June 1998, 46(2), pp. 207-233.

Branstetter, Lee and Sakakibara, Mariko. "When Do Research Consortia Work Well and Why?" Working paper, 2000, UC-Davis.

Callon, Scott. Divided Sun: MITI and the Breakdown of Japanese Industrial Policy, 1975-1993. Stanford: Stanford University Press, 1995.

Cohen, Wesley M. and Levinthal, Daniel A. "Innovation and Learning: The Two Faces of R\&D." Economic Journal, September 1989, 99(397), pp. 569-596.

d'Aspremont, Claude and Jacquemin, Alexis. "Cooperative and Noncooperative R\&D in a Duopoly with Spillovers.” American Economic Review, December 1988, 78(5), pp. 113337.

Ham, Rose Marie, and Mowery, David C. "Enduring Dilemmas in U.S. Technology Policy." California Management Review, Summer 1995, 37(4), pp. 89-107.

Irwin, Douglas A. and Klenow, Peter J. "High Tech R\&D Subsidies." Journal of International Economics, May 1996, 40(3-4), pp. 323-344.

Henderson, Rebecca, and Cockburn, Iain. "Scale, Scope, and Spillovers: The Determinants of Research Productivity in Drug Discovery." RAND Journal of Economics, Spring 1996, 27(1), pp. 32-59.

Jaffe, Adam B. "Technological Opportunity and Spillover of R\&D: Evidence from Firms' Patents, Profits, and Market Value." American Economic Review, December 1986, 76(5), pp. 984-1001.

Kamien, Morton I., Muller, Eitan, and Zang, Israel. "Research Joint Ventures and R\&D Cartels." American Economic Review, December 1992, 82(5), pp. 1293-1306.

Kamien, Morton I. and Zang, Israel. "Meet Me Halfway: Research Joint Ventures and Absorptive Capacity." International Journal of Industrial Organization, October 2000, 18(7), pp. 995-1012. 
Katsoulacos, Yannis and Ulph, David. "Endogenous Spillovers and Research Joint Ventures." Journal of Industrial Economics, September 1998, 44(3), pp. 333-57.

Katz, Michael L. "An Analysis of Cooperative Research and Development." RAND Journal of Economics, Winter 1986, 17(4), pp. 527-543.

Klette, Tor J., Moen, Jarle and Griliches, Zvi. "Do Subsidies to Commercial R\&D Reduce Market Failure? Microeconometic Evaluation Studies.” Research Policy, April 2000, 29(4-5), pp. 471-495.

Leahy, Dermot and Neary, J. Peter. "Public Policy Towards R\&D in Oligopolistic Industries." American Economic Review, September 1997, 87(4), pp. 642-662.

Levin, Richard C. and Reiss, Peter C. "Cost-reducing and Demand-creating R\&D with Spillovers." RAND Journal of Economics, Winter 1988, 19(4), pp. 538-556.

Moulton, B. "Random Group Effects and the Precision of Regression Estimates." Journal of Econometrics, August 1986, 32(3), pp. 385-397.

Porter, Michael E., Takeuchi, Hirotaka and Sakakibara, Mariko. Can Japan Compete?, New York: Basic Books, London: Macmillan, 2000.

Sakakibara, Mariko. Cooperative Research and Development: Theory and Evidence on Japanese Practice, Ph.D. Thesis, Harvard University, 1994.

Sakakibara, Mariko. "Heterogeneity of Firm Capabilities and Cooperative Research and Development: An Empirical Examination of Motives." Strategic Management Journal, July 1997a, 18(summer special issue), pp. 143-164.

Sakakibara, Mariko. "Evaluating Government Sponsored R\&D Consortia in Japan: Who Benefits and How?" Research Policy, December 1997b, 26(4-5), pp. 447-473.

Suzumura, Kotaro. "Cooperative and Noncooperative R\&D in an Oligopoly with Spillovers." American Economic Review, December 1992, 82(5), pp. 1307-20.

Spence, A. Michael. "Cost Reduction, Competition, and Industry Performance.” Econometrica, January 1984, 52(1), pp. 101-21.

Yano Research Institute. Market Share in Japan, Tokyo: Yano Research Institute, 1984, 1990. 


\section{DATA APPENDIX}

This data appendix briefly describes our data sources. A more detailed description of the data construction process is available from authors upon request.

Japanese Patent Data. Japanese patent data was obtained from the Japanese patent office and the Japan Patent Information Organization (JAPIO). Based on the descriptions of the technological goals of each consortium, officials of the Japanese patent office identified the classes of the Japanese patent system which were most closely related to those goals. We then acquired from JAPIO counts of patent applications in the targeted classes (as well as overall patent applications) for nearly 500 participating firms and control firms.

U.S. Patent Data. The data on patents taken out in the United States by Japanese firms were taken from the CASSIS CD-ROM, then matched to the REI database at Case Western Reserve University. Creating counts of U.S. patent grant data in the targeted classes required us to create a mapping from the International Patent Classification system to the classification system used by the U.S. Patent and Trademark Office.

R\&D data. The overall $R \& D$ spending of individual Japanese firms are taken from several consecutive issues of the Kaisha Shiki Ho, published by Toyo Keizai, and the Nikkei Kaisha Joho, published by the Nihon Keizai Shimbunsha. All R\&D expenditure data was deflated by the R\&D price index constructed by the Japanese Science and Technology Agency and reported in Gijutsu Yoran.

Other firm variables. Data on firm sales, industry affiliation, capital stock, and other variables are taken from various issues of the Japan Development Bank Corporate Finance Database.

Accounting for inputs in consortia. To measure and compare the real "R\&D productivity" enhancing effects of consortia, we need to account for the inputs that are invested into these consortia. While we know the official total budget of each consortium and the official duration of each consortium, we do not have detailed, consistent information on how these expenditures were allocated across participating firms and over time. We generally constrained to assume that expenditures were divided 
equally across participating firms and across years of the consortium's operation. However, even if we had perfect information on the allocation of expenditure across participating firms and over time, we must acknowledge that this would still not be a very accurate measure of the real contribution of firms. This is because we know from firm interviews that, when firms believed the technology being pursued within the research consortium had a high degree of commercial potential, they would often conduct a parallel research program on this technology within the firm, to maximize their own firm's ability to commercialize this technology upon the completion of the consortium. Because we have no way of measuring the distribution of a firms' $R \& D$ spending across different technologies at a particular point in time, we have no way of controlling for the existence of these parallel internal research programs.

Firms tended to participate in multiple consortia and consortia tended to target similar classes of technologies. Thus, there was a considerable degree of overlap in the consortia, both in terms of participating firms and targeted classes. The impact of previous consortia is captured by measures of pre-consortium patenting in the targeted technological classes. The impact of concurrent overlapping consortia is controlled for in the following manner. If firm $i$, currently participating in consortium $\mathrm{X}$ (the consortium of our focus) is also participating in consortium Y (an concurrent consortium), then firm $i$ 's of the total budget for consortium $\mathrm{Y}$ is multiplied by the degree of technological overlap between $\mathrm{X}$ and $\mathrm{Y}$ in terms of targeted patent classes, and this product is imputed to firm $i$ as "indirect inputs" to its participation in consortium X. A similar imputation is done for consortia that follow after $\mathrm{X}$ and target some of the same firms and classes. 